\title{
Hearing loss among patients on treatment for drug-resistant tuberculosis in Uganda
}

\author{
Lodiong Jackson Dumo Lodiong ${ }^{1}$, \\ Timbine Amos², Boniface Amanee Elias \\ Lumori $^{1}$ and Edwin Nuwagira ${ }^{1,2}$ \\ 1. Department of Internal Medicine, \\ Mbarara University of Science and \\ Technology \\ 2. Tuberculosis Treatment Unit, \\ Mbarara Regional Referral Hospital
}

Correspondence:

Lodiong Jackson Dumo Lodiong sebitjackson@hotmail.com

Submitted: February 2021

Accepted: July 2021

Published: August 2021

\section{Citation:}

Lodiong et al, Hearing loss among patients on treatment for drug-resistant tuberculosis in Uganda. South Sudan Medical Journal 2021;14(3):80-84 (C) 2021 The Author (s) License: This is an open access article under CC BY-NC-ND DOI: https://dx.doi.org/10.4314/ssmj.v14i3.3

\section{Abstract}

Introduction: Second-line injectable therapy using aminoglycosides (AG) like kanamycin, amikacin or capreomycin is associated with irreversible hearing loss. We aimed to determine the incidence and predictors of hearing loss among patients with drug resistant tuberculosis (DR-TB) who received AG.

Method: This was a retrospective cohort study conducted at the tuberculosis treatment unit of Mbarara Regional Referral Hospital (MRRH). All adult patients with a diagnosis of DR-TB between March 2016 and December 2019 were candidates for inclusion in the study. Hearing loss was defined as a hearing threshold of $>20$ decibels $(\mathrm{dB})$ at any test frequency in at least one ear. The incidence and predictors of hearing loss were analysed using multivariable Cox model. A p-value of $\leq 0.05$ was considered as statistically significant. Data analysis was done using STATA version 13.

Results: The estimated rate of developing hearing loss was 107 per 1000 person months. Thirty-seven (52.9\%) of 70 DR-TB patients experienced some degree of hearing loss, of which 25 (67.6\%) developed mild, 5 (13.5\%) moderate, and $3(8.1 \%)$ severe hearing loss. Male sex (HR 2.05, CI 1.03-4.10, p-value 0.041), increasing age (HR.5.17, CI 1.42-18.87, p-value 0.013) and high BMI (HR 3.31, CI 1.15 - 9.53, p-value 0.026) were significant predictors of new onset of hearing loss.

Conclusion: The incidence of hearing loss among DR-TB patients was high, with the majority having a mild hearing loss. Patients who were male, older, overweight and/or obese were more likely to develop AG-induced hearing loss.

Key words: Drug resistant tuberculosis, hearing loss, Uganda, aminoglycosides

\section{Introduction}

Tuberculosis (TB) still accounts for the highest mortality from any infectious diseases worldwide, even surpassing HIV/AIDs. ${ }^{[1]}$ Uganda has an incidence of TB of about 20/100,000 population where the prevalence of Multi-Drug Resistant TB (MDR - TB) in 2015 was estimated to be $1.6 \%$ among newly diagnosed TB cases and $12 \%$ among previously-treated cases. ${ }^{[2]}$

Drug resistant TB poses a threat to effective control due to the difficulties in diagnosis, the requirement for chemotherapy for up to two years, increased cost (up to 100 times more expensive than drug susceptible TB) and the use of more toxic second line drugs that are associated with increased adverse effects. ${ }^{[3]}$ The World Health Organization (WHO) 2016 DR-TB treatment Guidelines included recommendations on the use of a standardized shorter treatment regimen (sSTR) of 9 -12 months for patients with Rifampicin Resistant (RR)/ MDR-TB which includes the injectable drugs.

The WHO 2019 guidelines recommend that the modified bedaquiline-based therapy (a drug regimen which includes bedaquiline as the major drug), all oral shorter regimens (mSTR) may be used with close monitoring. Some groups of patients can still be put on the sSTR which includes the injectable drugs. ${ }^{[4]}$ 
At least $60 \%$ of patients on MDR-TB therapy will experience adverse events. ${ }^{[5]}$ Amongst the most serious side effects is irreversible ototoxicity which is caused by injectable second line agents, ${ }^{[6]}$ that are administered for a minimum period of six months as per the guidelines. Amikacin, kanamycin and capreomycin are ototoxic mainly through the loss of cochlear and/or vestibular sensory hair cells. ${ }^{[7]}$ The irreversible destruction of sensory cells in the cochlea leads to permanent hearing loss. It begins with the basal cochlea outer hair cells (responsible for high frequency sound) and then spreads to the apex (responsible for low frequency sound). Reactive oxygen species (free radicals) acting as mediators of the aminoglycoside (AG) toxicity appear to trigger cell death. ${ }^{[8]}$

In 2016 the Ugandan national guidelines for the treatment of DR-TB recommended the use of a bedaquiline-based injection-free shorter treatment regimen (the 'modified shorter regimen', mSTR), but based on the severity of the disease and the eligibility criteria for the mSTR, most groups of patients are still being put on the injectionbased regimen. There are limited data in our setting on the ototoxic effect of these injectable drugs among the DR-TB patients. This study focused on the incidence and predictors of hearing loss among DR-TB patients treated with the injectable AG based regimen.

\section{Method}

This was a retrospective cohort study, which aimed to determine the incidence and predictors of hearing loss in DR-TB patients, it was conducted in Mbarara Regional Referral Hospital TB unit in south-western Uganda. We used a retrospective cohort of 118 participants who were treated with injectable AG-based regimen between March 2016 and December 2019 who had received AG for at least six months. Patients with pre-existing hearing loss or without baseline and at least one follow-up audiometry report were excluded, leaving 70 participants whose information we analysed.

Hearing was tested at $125 \mathrm{~Hz}, 250 \mathrm{~Hz}, 500 \mathrm{~Hz}, 1000 \mathrm{~Hz}$, $2000 \mathrm{~Hz}, 4000 \mathrm{~Hz}$ and $8000 \mathrm{~Hz}$ frequencies. Hearing loss was defined as a hearing threshold of $>20$ decibels $(\mathrm{dB})$ at any test frequency in at least one ear. Hearing was measured by averaging the hearing thresholds at each visit for each ear separately. Hearing loss was categorized into mild $(21-40 \mathrm{~dB})$, moderate $(41-70 \mathrm{~dB})$, severe $(71-90$ $\mathrm{dB})$ and profound $(>=91 \mathrm{~dB})$.

Data were entered into Microsoft Excel version 10 and imported into STATA version 13. Baseline characteristics and degree of hearing loss were described in frequencies and percentages. We took the point of hearing loss to be at the first observation of hearing loss. Incidence rate for hearing loss per 1000 person-months were defined as the number of patients with hearing loss divided by the person-months at risk of hearing loss. We calculated the hazard ratios (HRs) and 95\% confidence intervals (CIs) using Cox proportional hazards regression analysis. We checked the assumptions of the Cox model graphically and with statistical tests.

\section{Table 1. Baseline characteristics}

\begin{tabular}{|c|c|}
\hline Characteristics & $\mathrm{N}=70(\%)$ \\
\hline Male sex: & $47(67.1)$ \\
\hline \multicolumn{2}{|l|}{ Age (years): } \\
\hline $15-30$ & $18(25.7)$ \\
\hline $31-45$ & $36(51.3)$ \\
\hline 46 and above & 16 (22.9) \\
\hline \multicolumn{2}{|l|}{ Body Mass Index (kg/m2): } \\
\hline Normal (18.5 - 24.9) & $39(55.7)$ \\
\hline Underweight $(<18.5)$ & $19(27.1)$ \\
\hline Overweight/Obese (>25) & $4(5.7)$ \\
\hline Missing & $8(11.4)$ \\
\hline History of smoking & $5(7.1)$ \\
\hline History of alcohol consumption* & $24(34.3)$ \\
\hline Positive HIV status & $44(62.9)$ \\
\hline History of previous TB infection & $27(38.6)$ \\
\hline \multicolumn{2}{|l|}{ Second- Line Anti-TB Drugs: } \\
\hline Kanamycin & $61(87.1)$ \\
\hline Capreomycin & 9 (12.9) \\
\hline \multicolumn{2}{|l|}{ Haemoglobin: } \\
\hline \multicolumn{2}{|l|}{ Normal } \\
\hline \multicolumn{2}{|l|}{$12-15.5 \mathrm{~g} / \mathrm{dl}$ for females and } \\
\hline \multicolumn{2}{|l|}{ Anaemic } \\
\hline $\begin{array}{l}<12.0 \mathrm{~g} / \mathrm{dl} \text { for females and } \\
<13.5 \mathrm{~g} / \mathrm{dl} \text { for males }\end{array}$ & 23 (32.9) \\
\hline \multicolumn{2}{|l|}{ Creatinine: } \\
\hline Normal (0.6 - $1.1 \mathrm{mg} / \mathrm{dl})$ & 65 (92.9) \\
\hline High & $2(2.9)$ \\
\hline Missing & $3(4.3)$ \\
\hline \multicolumn{2}{|l|}{ Gene Xpert Severity: } \\
\hline Low & $38(54.3)$ \\
\hline High & $29(41.4)$ \\
\hline Missing & $3(4.3)$ \\
\hline \multicolumn{2}{|l|}{ Smear Severity: } \\
\hline Paucibacillary & $54(77.1)$ \\
\hline Multibacillary & $14(20.0)$ \\
\hline Missing & $2(2.9)$ \\
\hline
\end{tabular}

*Any amount of alcohol 
Table 2. Degree of hearing loss

\begin{tabular}{ll} 
Degree of hearing loss $(>\mathbf{2 0 d B})$ & $\mathbf{n}(\%)$ \\
\hline Bilateral mild hearing loss $(21-40 \mathrm{~dB})$ & $25(67.6)$ \\
Bilateral moderate hearing loss $(41-70 \mathrm{~dB})$ & $5(13.5)$ \\
Bilateral severe hearing loss $(71-90 \mathrm{~dB})$ & $3(8.1)$ \\
Mixed hearing loss* (mild and moderate) & $4(10.8)$
\end{tabular}

*Means the patient's degree of hearing loss in left ear is different from the loss in the right ear

\section{Results}

We extracted 118 files for patients who were treated for DR-TB from the TB record centre. Eighteen patients had no audiogram records, 14 had no baseline audiogram and 16 had no follow-up audiograms, so 70 patients were enrolled, all of them were assessed on a monthly basis until the end of the sixth month. There were 47 (67.1\%) males. Fifty-one percent were aged between $31-45$ years; 44 (62.9\%) were HIV positive and $61(87.1 \%)$ were on kanamycin. Twenty-nine $(41.4 \%)$ had high gene x-pert severity (i.e., high load of Mycobacterium tuberculosis complex detection in Xpert) and 54 (77.1\%) had paucibacillary smear severity (i.e., low bacterial load of Mycobacterium tuberculosis in the sputum smear). The baseline characteristics are shown in Table 1 .

Twenty-five patients (67.6\%) developed mild, five (13.5\%) moderate, three $(8.1 \%)$ severe and four $(10.8 \%)$ mixed (mild/ moderate) hearing loss (Table 2). Twentyfive patients $(67.6 \%)$ had bilateral and $12(32.4 \%)$ had unilateral hearing loss ( 8 in the right ear and 4 in the left ear).

The estimated rate of developing hearing loss was 107 per 1000 person months (CI 77 - 147); the minimum time for developing hearing loss was two months and the mean was four months (as shown in Kaplan Meier curve - Figure 1). The cumulative incidence over a period of six months was $52.9 \%$ (37 out of 70 patients developed hearing loss).

In the adjusted multivariable Cox model, male sex, older age and high BMI $\geq 25 \mathrm{~kg} / \mathrm{m} 2$ were associated significantly with hearing loss (Table 3 ).

\section{Discussion}

Our study showed a hearing loss incidence of 53\% after the injectable phase which is similar to the study of Harris et al in South Africa which found 58\% hearing loss among their cohort. ${ }^{[9]}$ This is probably because of the similarities in the patients' characteristics. In our study, however, HIV infection did not predict hearing loss during DR-TB treatment, which conflicts with the finding of Harris et $\mathrm{al}^{[9]}$ who demonstrated a strong positive association with HIV infection.
Table 3. Predictors of hearing loss

\begin{tabular}{|c|c|c|}
\hline Characteristics & $\operatorname{AHR}(95 \% \mathrm{CI})$ & p-value \\
\hline \multicolumn{3}{|l|}{ Sex: } \\
\hline \multicolumn{3}{|l|}{ Female } \\
\hline Male & $2.05(1.03-4.10)$ & 0.041 \\
\hline \multicolumn{3}{|l|}{ Age (years): } \\
\hline \multicolumn{3}{|l|}{$15-30$} \\
\hline $31-45$ & $5.17(1.42-18.87)$ & 0.013 \\
\hline 46 and above & $4.85(1.30-18.27)$ & 0.020 \\
\hline \multicolumn{3}{|l|}{ Regimen: } \\
\hline \multicolumn{3}{|l|}{ Capreomycin } \\
\hline Kanamycin & $0.53(0.20-1.40)$ & 0.201 \\
\hline \multicolumn{3}{|l|}{ Previous TB: } \\
\hline \multicolumn{3}{|l|}{ No } \\
\hline Yes & $0.77(0.39-1.50)$ & 0.428 \\
\hline \multicolumn{3}{|l|}{ HIV status: } \\
\hline \multicolumn{3}{|l|}{ Negative } \\
\hline Positive & $0.87(0.36-2.13)$ & 0.765 \\
\hline \multicolumn{3}{|l|}{ BMI (kg/m2): } \\
\hline \multicolumn{3}{|l|}{ Normal (18.5 - 24.9) } \\
\hline Underweight $(<18.5)$ & $1.10(0.92-4.24)$ & 0.081 \\
\hline $\begin{array}{l}\text { Overweight/Obese } \\
(\geq 25)\end{array}$ & $3.31(1.15-9.53)$ & 0.026 \\
\hline \multicolumn{3}{|l|}{ Creatinine: } \\
\hline \multicolumn{3}{|l|}{$\begin{array}{l}\text { Normal } \\
(0.6-1.1 \mathrm{mg} / \mathrm{dl})\end{array}$} \\
\hline High & $0.73(0.13-4.01)$ & 0.713 \\
\hline \multicolumn{3}{|l|}{ Gene X.pert Severity: } \\
\hline \multicolumn{3}{|l|}{ Low } \\
\hline High & $0.96(0.41-2.23)$ & 0.938 \\
\hline \multicolumn{3}{|l|}{$\begin{array}{l}\text { History of alcohol } \\
\text { consumption*: }\end{array}$} \\
\hline \multicolumn{3}{|l|}{ No } \\
\hline Yes & $1.42(0.66-3.10)$ & 0.371 \\
\hline \multicolumn{3}{|l|}{ Smoking History: } \\
\hline \multicolumn{3}{|l|}{ No } \\
\hline Yes & $2.70(0.71-10.12)$ & 0.146 \\
\hline
\end{tabular}

Key: AHR: Adjusted Hazard Ratio, Cl: Confidence Interval *Any amount of alcohol 


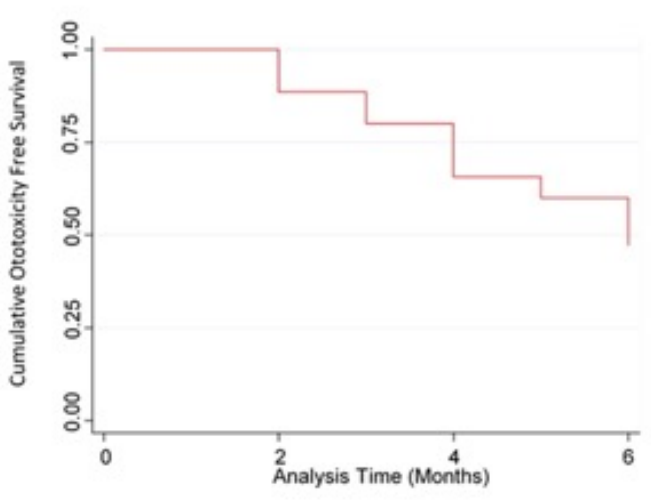

Figure 1. Kaplan-Meier Hearing Loss Estimate

In our study male sex, increasing age and high BMI predicted new onset hearing loss. Sharma et al also found that males were more likely to develop hearing loss than females. ${ }^{[10]}$

Hong et al. in South Africa also reported that older age and obese patients are at a higher risk of developing hearing loss. ${ }^{[1]}$ Ageing leads to a decrease in hair cells in the cochlea and reduction in endogenous protective mechanisms such as antioxidants which may increase the susceptibility to ototoxic effects. ${ }^{[12]}$ Obesity may lead to hearing loss as adipose tissue secretes pro-inflammatory cytokines causing inflammation and end-organ damage. [13]

We also found that $67.6 \%$ of our cohort developed mild hearing loss. A prospective study of DR-TB patients treated with injectable AG in Pakistan reported that $60 \%$ of their patients developed mild hearing loss. ${ }^{[14]}$ However, our study might have underestimated the degree of occurrence of hearing loss because of missing follow-up audiograms. In another prospective study in Zambia, $46 \%$ of patients developed severe hearing loss at the end of the AG treatment which is much higher than our $8.1 \% .{ }^{[15]}$ The prospective nature of their study may have facilitated regular audiometry checks throughout the study period.

\section{Conclusion and recommendation}

Over half of the DR-TB patients in our study developed a degree of hearing loss after six months of treatment. The majority developed mild hearing loss and the minimum time for the occurrence of hearing loss was two months. Male sex, older age, and overweight (BMI $>=25 \mathrm{~m} 2)$ predicted hearing loss.

Therefore, based on our findings, we advocate the use of the new non-aminoglycoside medicines e.g., bedaquiline.
Conflict of Interest: None

Source of Funding: None

References

1. Harding EJTLRM. WHO global progress report on tuberculosis elimination. The Lancet Respiratory Medicine. 2020;8(1):19. https://doi. org/10.1016/s2213-2600(19)30418-7

2. Okethwangu D, Birungi D, Biribawa C, Kwesiga $B$, Turyahabwe S, Ario AR, et al. Multidrugresistant tuberculosis outbreak associated with poor treatment adherence and delayed treatment: Arua District, Uganda, 2013-2017. BMC infectious diseases. 2019;19(1):1-10. https://bmcinfectdis. biomedcentral.com/articles/10.1186/s12879019-4014-3

3. Khawbung JL, Nath D, Chakraborty SJCI, Microbiology, Diseases I. Drug resistant Tuberculosis: A review. Comparative Immunology, Microbiology and Infectious Diseases. 2020:101574. DOI: 10.1016/j. cimid.2020.101574

4. Khan U, Huerga $H$, Khan AJ, Mitnick CD, Hewison C, Varaine F, et al. The endTB observational study protocol: treatment of MDRTB with bedaquiline or delamanid containing regimens. BMC infectious diseases. 2019;19(1):19. https://doi.org/10.1186/s12879-019-4378-4

5. Bloss E, Kukša L, Holtz T, Riekstina V, Skripčonoka $\mathrm{V}$, Kammerer $\mathrm{S}$, et al. Adverse events related to multidrug-resistant tuberculosis treatment, Latvia, 2000-2004. The International journal of tuberculosis and lung disease. 2010;14(3):275-81. https://pubmed.ncbi.nlm.nih.gov/20132617/

6. Bardien S, Jong Gd, Schaaf HS, Harris T, Fagan J, Petersen LJSSAMJ. Aminoglycoside-induced hearing loss: South Africans at risk. SAMJ: South African Medical Journal. 2009;99(6):440-1. https://hdl.handle.net/10520/EJC69500

7. Talaska AE, Schacht J, Fischel-Ghodsian NJDDTDM. Molecular and genetic aspects of aminoglycoside-induced hearing loss. Drug Discovery Today: Disease Mechanisms. 2006;3(1):119-24. https://doi.org/10.1016/j. ddmec.2006.03.010

8. Hong H, Dooley KE, Starbird LE, Francis HW, Farley JEJAot. Adverse outcome pathway for aminoglycoside ototoxicity in drug-resistant tuberculosis treatment. Archives of toxicology. 2019;93(5):1385-99. DOI: 10.1007/s00204-01902407-8 
9. Harris T, Bardien S, Schaaf HS, Petersen L, De Jong G, Fagan JJJSAMJ. Aminoglycoside-induced hearing loss in HIV-positive and HIV-negative multidrug-resistant tuberculosis patients. South African Medical Journal. 2012;102(6). DOI: 10.7196/samj.4964

10. Sharma V, Bhagat S, Verma B, Singh R, Singh SJIjoo. Audiological evaluation of patients taking kanamycin for multidrug resistant tuberculosis. Iranian journal of otorhinolaryngology. 2016;28(86):203. https://pubmed.ncbi.nlm.nih. gov/27429949/

11. Hong H. Risk of Aminoglycoside-Induced Hearing Loss among Patients with Drug-Resistant Tuberculosis in South Africa: Johns Hopkins University; 2018. http://jhir.library.jhu.edu/ handle/1774.2/61208

12. Tavanai E, Mohammadkhani GJEAoO-R-L. Role of antioxidants in prevention of age-related hearing loss: a review of literature. European Archives of Oto-Rhino-Laryngology. 2017;274(4):1821-34. https://doi.org/10.1007/s00405-016-4378-6
13. Hwang JH, Hsu CJ, Liu TC, Yang WSJCe. Association of plasma adiponectin levels with hearing thresholds in adults. Clinical endocrinology. 2011;75(5):614-20. https://doi. org/10.1111/j.1365-2265.2011.04090.x

14. Achakzai A, Achakzai MA, Achakzai H, Baqi A, Achakzai MJPJMHS. Frequency of Sensorineural Hearing Loss in Patients with Drug Resistant Pulmonary Tuberculosis. Pak J Med Health Sci. 2020;14(2):478-9. https://pjmhsonline. com/2020/apr-june/478.pdf

15. Mwansasu C, Siziya S, Mpondo BJTHP. Hearing Loss among Multi-Drug Resistant Tuberculosis patients on Kanamycin in Ndola Teaching Hospital, Zambia: Study of ototoxicity and practice. The Health Press. 2017:72. https:// akros.com/wp-content/uploads/2017/11/THPZ_ V1_I4.pdf\#page $=72$ 